\title{
Overexpression of microRNA-448 inhibits osteosarcoma cell proliferation and invasion through targeting of astrocyte elevated gene-1
}

\author{
WEIBO JIANG $^{1}$, SHU WANG $^{2}$, YANG SUN ${ }^{1}$, YING JIANG ${ }^{3}$, TAO YU ${ }^{1}$ and JINCHENG WANG ${ }^{1}$ \\ Departments of ${ }^{1}$ Orthopaedics, ${ }^{2}$ Radiotherapy and ${ }^{3}$ Thyroid Surgery, The Second Hospital of Jilin University, \\ Changchun, Jilin 130041, P.R. China
}

Received October 16, 2016; Accepted June 13, 2017

DOI: $10.3892 / \mathrm{mmr} .2017 .7249$

\begin{abstract}
MicroRNAs (miRNAs/miRs) have been implicated in the development and progression of osteosarcoma. miR-448 is emerging as a tumor-associated miRNA in many human cancers. However, the role of $\mathrm{miR}-448$ in osteosarcoma remains unknown. The present study aimed to identify the potential role of miR-448 in osteosarcoma. It was demonstrated that miR-448 was significantly downregulated in osteosarcoma cell lines, as detected by reverse transcription-quantitative polymerase chain reaction (RT-qPCR). miR-448 mimics were transfected into osteosarcoma cells to overexpress miR-448. Overexpression of miR-448 markedly inhibited cell proliferation and invasion in osteosarcoma cells. Bioinformatics and luciferase reporter assays demonstrated that astrocyte elevated gene-1 (AEG-1) was a target gene of miR-448. RT-qPCR and western blot analysis revealed that miR-448 inhibited AEG-1 expression. Further data revealed that miR-448 overexpression impeded the Wnt and nuclear factor- $\kappa \mathrm{B}$ signaling pathways. However, restoration of AEG-1 expression could abolish the miR-448-mediated antitumor effects. Taken together, these findings suggested that miR-448 may inhibit osteosarcoma development by targeting AEG-1, providing a novel candidate miRNA for development of miRNA-targeted therapies for osteosarcoma.
\end{abstract}

Correspondence to: Mr. Jincheng Wang, Department of Orthopaedics, The Second Hospital of Jilin University, 218 Ziqiang Street, Changchun, Jilin 130041, P.R. China

E-mail: wang_jinchengjc@163.com

Abbreviations: miRNAs, microRNAs; RT-qPCR, reverse transcription-quantitative polymerase chain reaction; AEG-1,

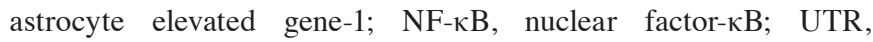
untranslated region

Key words: astrocyte elevated gene-1, miR-448, osteosarcoma, cell proliferation, cell invasion

\section{Introduction}

Osteosarcoma is the most prevalent malignancy of the bone in the pediatric age group (1). Despite progress in cancer therapies over the past decades, the prognosis of osteosarcoma is still poor, with a survival rate of $<30 \%$ (2). However, the precise molecular mechanism of osteosarcoma pathogenesis remains elusive. Therefore, it is of great importance to achieve a better understanding of the molecular pathogenesis of osteosarcoma, which could help to improve its diagnosis, prognosis and potential treatment.

MicroRNAs (miRNAs/miRs) are a class of endogenous, non-coding RNAs ( 22 nucleotides), which regulate gene expression through targeting the 3'-untranslated region (UTR) of the mRNA, leading to translation inhibition $(3,4)$. Thus, miRNAs function as inhibitors of gene expression. miRNAs regulate a series of cellular processes, including proliferation, apoptosis, differentiation, migration and invasion (5). An increasing number of studies suggest that miRNAs are frequently dysregulated in various cancers, functioning as oncogenes or tumor suppressors (6-8). Previous reports have suggested that miRNAs serve an important role in the pathogenesis of osteosarcoma (9-11). A better understanding of miRNAs in osteosarcoma will aid the development of miRNA-targeted therapies. However, the role of miRNAs in osteosarcoma remains elusive.

Astrocyte elevated gene-1 (AEG-1), also known as metadherin or lysine-rich carcinoembryonic antigen-related cell adhesion molecule, has been recognized as an oncogene in various cancers (12-15). AEG-1 was originally characterized as a human immunodeficiency virus-1 and tumor necrosis factor- $\alpha$-inducible gene in human fetal astrocytes (16). AEG-1 was identified to be overexpressed in various cancers associated with cancer cell proliferation, metastasis, angiogenesis, and chemoresistance $(17,18)$. AEG-1 is a target gene of oncogenic HRas that activates phosphatidylinositol 3-kinase (PI3K) and c-Myc (19). AEG-1 activates cell survival pathways through $\mathrm{PI} 3 \mathrm{~K} /$ protein kinase B (Akt) signaling (20). AEG-1 promotes tumor progression and metastasis through activation of nuclear factor- $\kappa \mathrm{B}(\mathrm{NF}-\kappa \mathrm{B})$ and Wnt signaling pathways $(21,22)$. It is reported that AEG-1 is overexpressed in osteosarcoma and it promotes proliferation, metastasis, and chemoresistance 
against osteosarcoma (23-25). Therefore, therapy targeting AEG-1 inhibition may have promising therapeutic effects on osteosarcoma.

A growing body of evidence has reported that miR-448 functions as a putative tumor suppressor in various cancers by targeting and inhibiting various oncogenes (26-28). However, the role of miR-448 in osteosarcoma is unclear. In the present study, the potential role of miR-448 in osteosarcoma was investigated. The results revealed that miR-448 was downregulated in osteosarcoma cell lines. Overexpression of miR-448 significantly inhibited osteosarcoma cell proliferation and invasion. Furthermore, AEG-1 was identified as the functional target of miR-448 in osteosarcoma cells. However, restoration of AEG-1 expression could abolish miR-448-mediated antitumor effect effects. The present study suggested that miR-448 may inhibit osteosarcoma development by targeting AEG-1, providing a novel candidate mechanism for miRNA-targeted therapies.

\section{Materials and methods}

Cell lines. The 143B, SaOS-2, U2OS and MG63 human osteosarcoma cell lines and the hFOB human normal fetal osteoblastic cell line were purchased from the American Type Culture Collection (Manassas, VA, USA) and routinely cultured in Dulbecco's modified Eagle's medium (DMEM; Invitrogen; Thermo Fisher Scientific Inc., Waltham, MA, USA) containing $10 \%$ fetal bovine serum (FBS; Gibco; Thermo Fisher Scientific Inc.) and 1\% penicillin-streptomycin solution (Gibco; Thermo Fisher Scientific Inc.). Cells were maintained in a humidified incubator ( $95 \%$ relative humidity) containing $5 \% \mathrm{CO}_{2}$ at $37^{\circ} \mathrm{C}$.

$R N A$ isolation and reverse transcription-quantitative polymerase chain reaction ( $R T-q P C R)$. Total RNA was isolated using TRIzol reagent (Invitrogen; Thermo Fisher Scientific Inc.) according to the manufacturer's protocol. In order to detect AEG-1 mRNA expression, cDNA was synthesized by Moloney-murine leukemia virus (M-MLV) reverse transcriptase (BioTeke Corporation, Beijing, China). Briefly, a $20 \mu \mathrm{l}$ reaction mixture, including $1 \mu \mathrm{g}$ total RNA, $2 \mu$ l Oligo (dT) primer, $4 \mu \mathrm{l}$ M-MLV buffer, $1 \mu \mathrm{l}$ dNTPs, $1 \mu \mathrm{l}$ M-MLV reverse transcriptase and $12 \mu \mathrm{l}$ nuclease-free water was incubated at $42^{\circ} \mathrm{C}$ for $60 \mathrm{~min}$. In order to detect miR-448 mRNA expression, cDNA was synthesized by using the TaqMan MicroRNA Reverse Transcription kit (Applied Biosystems; Thermo Fisher Scientific Inc.). Briefly, a $15 \mu$ l reaction mixture, including $5 \mu 1$ total RNA, $3 \mu 1$ RT primer, $0.15 \mu 1$ dNTPs, $1.5 \mu 1$ reverse transcription buffer, $1 \mu \mathrm{l}$ reverse transcriptase, $0.19 \mu \mathrm{l}$ RNase inhibitor, and $4.16 \mu \mathrm{l}$ nuclease-free water was incubated at $16^{\circ} \mathrm{C}$ for $30 \mathrm{~min}$, at $42^{\circ} \mathrm{C}$ for $30 \mathrm{~min}$ and at $85^{\circ} \mathrm{C}$ for $5 \mathrm{~min}$. For qPCR, a $20 \mu 1$ reaction mixture was used, including $10 \mu \mathrm{lSYBR}$ Green PCR Master Mix (Applied Biosystems; Thermo Fisher Scientific, Inc.), $2 \mu \mathrm{l}$ of each forward and reverse primer, $2 \mu \mathrm{l}$ cDNA and $6 \mu$ l nuclease-free water. qPCR was performed on a 7900HT Fast Real-Time PCR System (Applied Biosystems Thermo Fisher Scientific Inc.) under the following conditions: Initial denaturation at $94^{\circ} \mathrm{C}$ for $5 \mathrm{~min}$, followed by 35 cycles $\left(94^{\circ} \mathrm{C}\right.$ for $20 \mathrm{sec}, 55^{\circ} \mathrm{C}$ for $25 \mathrm{sec}$, and $72^{\circ} \mathrm{C}$ for $35 \mathrm{sec}$ ), with a final extension step at $72^{\circ} \mathrm{C}$ for $10 \mathrm{~min}$. The fold-change in gene expression was calculated using the $2^{-\Delta \Delta \mathrm{Cq}}$ method (29).
GAPDH was used as internal control for normalization of AEG-1 mRNA expression. U6 small nuclear (sn)RNA was used as internal control for normalization of miR-448 mRNA expression. The primers used were as follows: AEG-1 forward, 5'-CGAGAAGCCCAAACCAAATG-3' and reverse, 5'-TGG TGGCTGCTTTGCTGTT-3'; GAPDH forward, 5'-TGTGTC CGTCGTGGATCTGA-3' and reverse, 5'-TTGCTGTTGAAG TCGCAGGAG-3'; miR-448 forward, 5'-TTATTGCGATGT GTTCCTTATG-3' and reverse, 5'-ATGCATGCCACGGGC ATATACACT-3'; and U6 snRNA forward, 5'-GCTTCGGCA GCACATATACTAAAAT-3' and reverse, 5'-CGCTTCACG AATTTGCGTGTCAT-3'.

Cell transfection. miR-448 mimics (5'-UUGCAUAUGUAG GAUGUCCCAU-3') and negative control miRNA (miR-NC; 5'-UCCGAGAGGCAGGCCUUGGAUU-3') were purchased from Guangzhou RiboBio Co., Ltd. (Guangzhou, China) and transfected into cells at a final concentration of $50 \mathrm{nM}$. AEG-1 cDNA was amplified by PCR using specific primers (forward, 5'-GCCACCATGGCTGCAGGAGCTG-3' and reverse, 5'-AAATAGCCAGCCTATCAAGACTC-3'). The AEG-1 cDNA without the 3'-UTR was inserted into the pcDNA3.1 vector (Guangzhou RiboBio Co., Ltd.). The miRNAs and vectors were transfected into cells using Lipofectamine 2000 (Invitrogen; Thermo Fisher Scientific Inc.) following the manufacturer's protocol and incubated for $48 \mathrm{~h}$ at $37^{\circ} \mathrm{C}$.

MTT assays. Cells were seeded into 96-well plates at a density of $5 \times 10^{3}$ cells/well in DMEM. After $24 \mathrm{~h}$, cells were transfected with miR-448 mimics or miR-NC and incubated for $48 \mathrm{~h}$ at $37^{\circ} \mathrm{C}$. The medium was then replaced with fresh DMEM and $20 \mu \mathrm{l}$ MTT was added to each well. After $4 \mathrm{~h}$ of incubation at $37^{\circ} \mathrm{C}$, the medium was removed and $200 \mu \mathrm{l}$ dimethyl sulfoxide (Sigma-Aldrich; Merck KGaA, Darmstadt, Germany) was added to dissolve the formazan crystals. Finally, the absorbance was detected at $490 \mathrm{~nm}$ using an ELISA microplate reader (Bio-Rad Laboratories, Inc., Hercules, CA, USA).

Colony formation assays. After transfection with miR-448 mimics or miR-NC for $48 \mathrm{~h}$, cells were seeded into 6-well plates at a density of 1,000 cells/well in DMEM containing $0.3 \%$ noble agar (Sigma-Aldrich; Merck KGaA), for 10 days. Colonies were then stained with $1 \%$ crystal violet for $30 \mathrm{~min}$ at room temperature (Sigma-Aldrich; Merck KGaA). Finally, colonies (containing $\geq 50$ cells) were counted under an Olympus IX73 inverted microscope (Olympus Corporation, Tokyo, Japan).

Invasion assays. For cell invasion assays, the upper chambers of Transwell inserts (Corning Inc., Corning, NY, USA) were pre-coated with Matrigel (BD Biosciences, Franklin Lakes, San Jose, CA, USA). After transfection at $37^{\circ} \mathrm{C}$ with miR-448 mimics or miR-NC for $48 \mathrm{~h}, 1 \times 10^{5}$ cells were resuspended in $500 \mu \mathrm{l}$ serum-free medium and were added to the upper chambers. Meanwhile, the lower chamber was filled with $500 \mu \mathrm{l}$ growth medium containing $10 \%$ FBS. After incubation at $37^{\circ} \mathrm{C}$ for $24 \mathrm{~h}$, filters were removed and the non-invaded cells on the upper surface were removed using cotton swabs. The invaded cells were fixed with $20 \%$ methanol for $15 \mathrm{~min}$ at room temperature and stained with $1 \%$ crystal violet for $5 \mathrm{~min}$ 
A

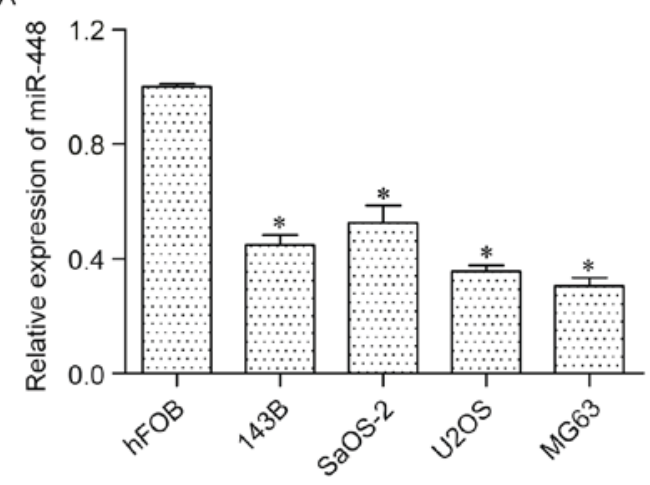

B

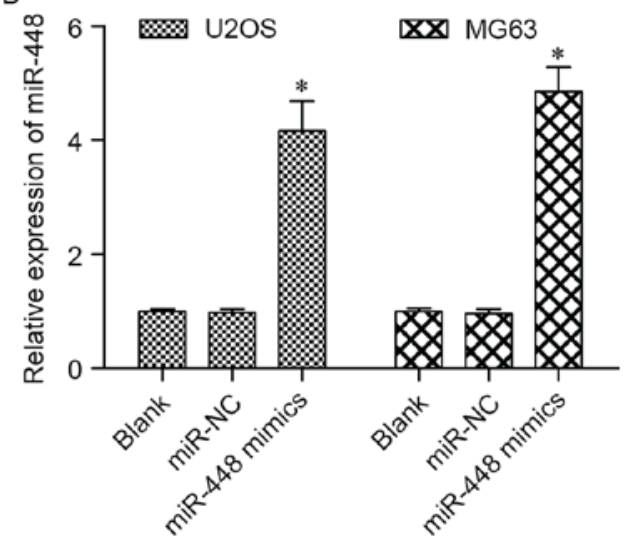

Figure 1. mRNA expression levels of miR-448 in osteosarcoma cells studied by reverse transcription-quantitative polymerase chain reaction. (A) mRNA expression levels of miR-448 in 143B, SaOS-2, U2OS, MG63 and hFOB cell lines. "P<0.05 vs. hFOB. (B) mRNA expression levels of miR-448 in U2OS and MG63 cells transfected with miR-448 mimics or miR-NC. ${ }^{*} \mathrm{P}<0.05$ vs. blank and miR-NC. Data are expressed as the mean \pm standard deviation. miR, microRNA; NC, negative control.

at room temperature. Invasion was analyzed by counting cells in 5 randomly selected fields under an Olympus CX41 microscope (Olympus Corporation).

Western blot analysis. Proteins were isolated from cells $\left(2 \times 10^{6}\right)$ using radioimmunoprecipitation assay lysis buffer (Beyotime Institute of Biotechnology, Haimen, China) for $5 \mathrm{~min}$ at room temperature. Supernatants were collected following centrifugation at $14,000 \times \mathrm{g}$ for $15 \mathrm{~min}$ at $4^{\circ} \mathrm{C}$. Protein concentration was determined using a bicinchoninic acid protein assay (Beyotime Institute of Biotechnology). Equal amounts of extracted protein samples $(40 \mu \mathrm{g})$ were separated by $12.5 \%$ SDS-PAGE and transferred onto a nitrocellulose membrane. After blocking with $3 \%$ nonfat milk at $37^{\circ} \mathrm{C}$ for $1 \mathrm{~h}$, the membrane was probed with the following primary antibodies (Merck KGaA): Anti-AEG-1 (cat. no. HPA015104; 1:500) and anti-GAPDH (cat. no. SAB4300645; 1:800) at $4^{\circ} \mathrm{C}$ overnight. The membrane was washed with TBS containing $0.05 \%$ Tween-20 followed by incubation with horseradish peroxidase-conjugated secondary antibodies (cat. no. bs-0295G-HRP; 1:2,000; Bioss, Beijing, China) for $2 \mathrm{~h}$ at room temperature. The protein bands were visualized using enhanced chemiluminescence (EMD Millipore, Billerica, MA, USA). Blots were semi-quantified by densitometry using Image-Pro Plus software version 6.0 (Media Cybernetics, Inc., Rockville, MD, USA). The fold-change of protein expression was obtained by normalization with GAPDH and then compared with the control group.

Luciferase reporter assays. The putative targets of miR-448 were predicted using publicly available databases TargetScan (http://www.targetscan.org) and miRanda (http://www.microrna.org). In order to detect the prediction between miR-448 and AEG-1 3'-UTR, AEG-1-3'-UTR (Sangon Biotech, Co., Ltd., Shanghai, China) containing the predicted seed sequence of miR-448 or a mutated binding site of the 3'-UTR were inserted into the dual-luciferase plasmid pmirGLO (Promega Corporation, Madison, WI, USA). The mutant AEG-1 3'-UTR was synthesized using the QuikChange Multi Site-Directed Mutagenesis kit (Agilent Technologies,
Inc., Santa Clara, CA, USA). The pmirGLO-AEG-1-3'-UTR vector $(0.5 \mathrm{ng} / \mu \mathrm{l})$ was co-transfected with $\mathrm{miR}-448$ mimics $(50 \mathrm{nM})$ into osteosarcoma cells using Lipofectamine 2000 (Invitrogen; Thermo Fisher Scientific Inc.) for $48 \mathrm{~h}$ at $37^{\circ} \mathrm{C}$. In order to detect Wnt signaling, cells were co-transfected with miR-448 mimics (50 nM), TOPFlash firefly luciferase reporter vector $(0.5 \mathrm{ng} / \mu \mathrm{l})$, and phRL-TK Renilla luciferase vectors $(0.2 \mathrm{ng} / \mu \mathrm{l}$; all from Promega Corporation). In order to detect $\mathrm{NF}-\kappa \mathrm{B}$ signaling, cells were co-transfected with miR-448 mimics $(50 \mathrm{nM}), \mathrm{pNF}-\kappa \mathrm{B}$-luciferase vector $(0.5 \mathrm{ng} / \mu 1$; Promega Corporation). After $48 \mathrm{~h}$, the luciferase activity in $1 \times 10^{6}$ cells was measured using the Dual-Luciferase assay kit (Promega Corporation). Firefly luciferase activity was normalized to Renilla luciferase activity for each well to normalize cell number and transfection efficiency.

Statistical analysis. Data are expressed as the mean \pm standard deviation of at least 3 independent experiments. Statistical analyses were performed using SPSS software version 11.5 (SPSS, Inc., Chicago, IL, USA). Differences were analyzed by one-way analysis of variance followed by Bonferroni's post hoc test. $\mathrm{P}<0.05$ was considered to indicate a statistically significant difference.

\section{Results}

Downregulation of miR-448 in osteosarcoma cells. In order to investigate the expression pattern of miR-448 in osteosarcoma, the expression of miR-448 in 143B, SaOS-2, U2OS and MG63 osteosarcoma cell lines was studied by RT-qPCR. The results demonstrated that miR-448 was significantly downregulated in osteosarcoma cell lines compared with the hFOB normal fetal osteoblastic cell line (Fig. 1A). Because miR-448 mRNA expression levels in U2OS and MG63 cells were lower, these two cell lines were chosen for subsequent analysis.

Overexpression of miR-448 inhibits osteosarcoma cell proliferation. In order to investigate the possible role of miR-448 in osteosarcoma, miR-448 was overexpressed in U2OS and 
A

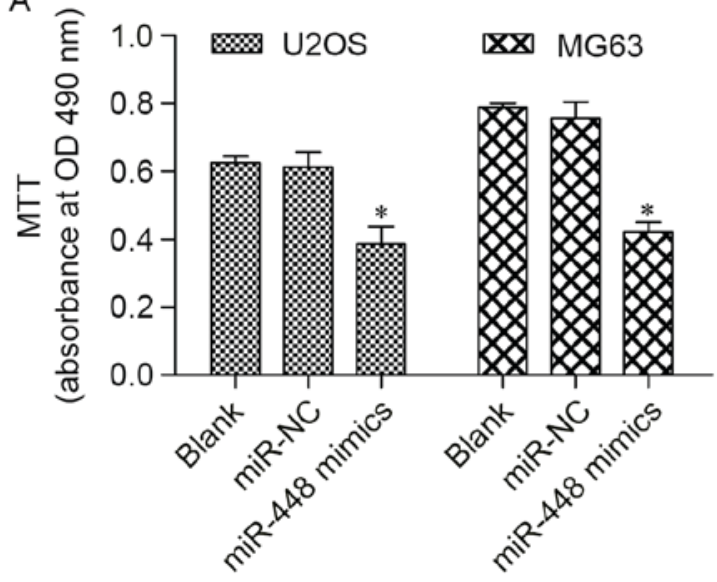

B

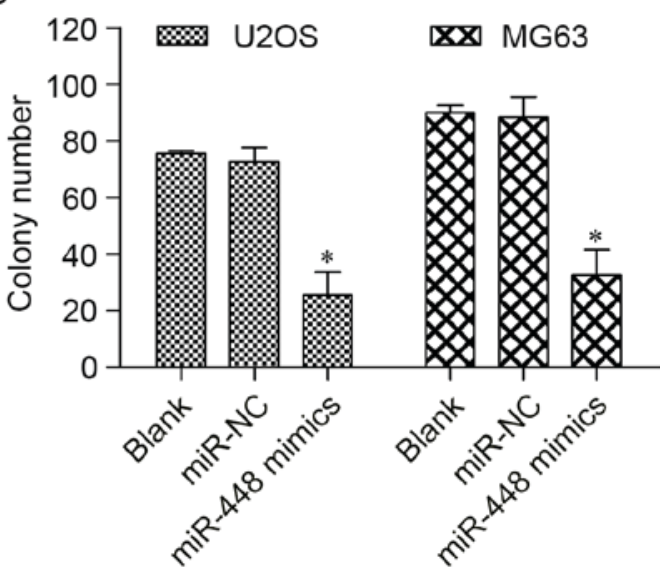

Figure 2. Effects of miR-448 on cell proliferation, as determined by (A) MTT and (B) colony formation assays, in U2OS and MG63 cells. Data are expressed as the mean \pm standard deviation. " $\mathrm{P}<0.05$ vs. blank and miR-NC. miR, microRNA; NC, negative control; OD, optical density.

A

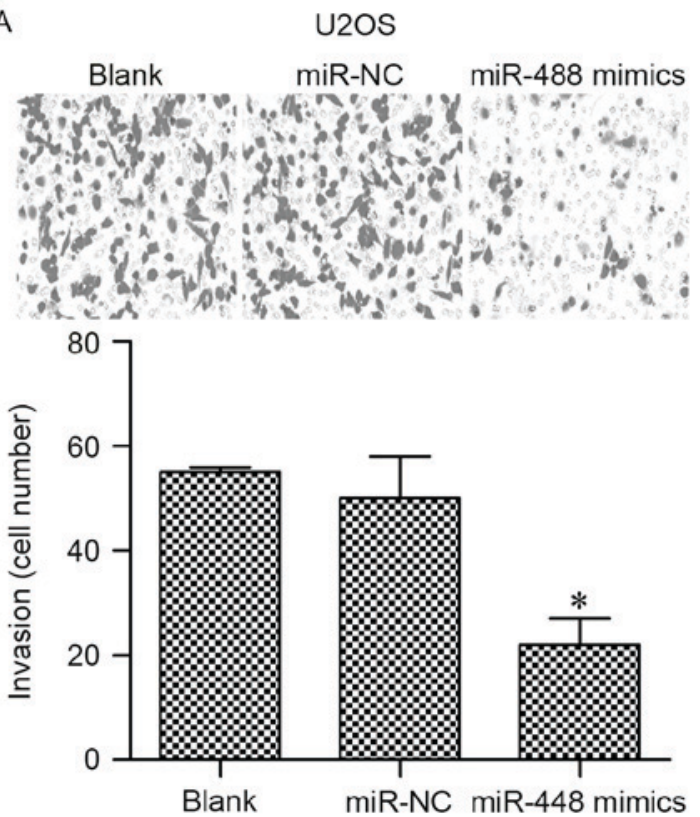

B
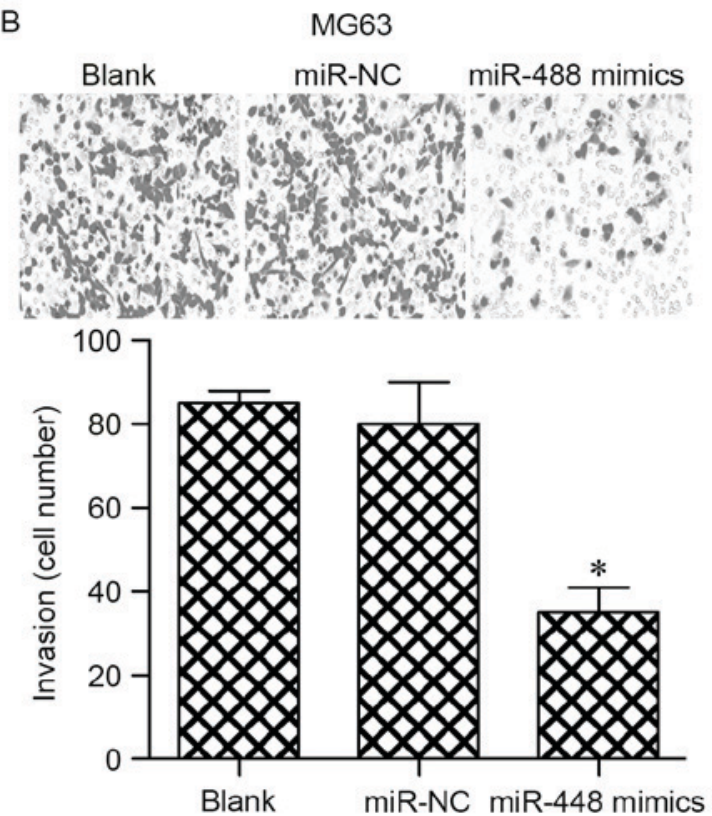

Figure 3. Effects of miR-448 overexpression on (A) U2OS and (B) MG63 cells as detected by Transwell invasion assays. Photomicrographs were captured under magnification, $x 400$. Data are expressed as the mean \pm standard deviation. " $\mathrm{P}<0.05$ vs. blank and miR-NC. miR, microRNA; NC, negative control.

MG63 cells by transient transfection with miR-448 mimics (Fig. 1B). The effects of miR-448 overexpression on osteosarcoma cell proliferation were investigated next by MTT assays. The results demonstrated that overexpression of miR-448 markedly inhibited cell proliferation of osteosarcoma cells (Fig. 2A). The inhibitory effect of miR-448 on proliferation was further detected by colony formation assays. The results demonstrated that the colony-forming capacity of osteosarcoma cells was significantly reduced by miR-448 overexpression (Fig. 2B). Taken together, these results indicated that miR-448 inhibits osteosarcoma cell proliferation.

Overexpression of miR-448 inhibits osteosarcoma cell invasion. To further investigate the function of miR-448 in osteosarcoma cells, the effect of miR-448 overexpression on cell invasion was studied by Transwell invasion assays. The results illustrated that miR-448 overexpression significantly reduced cell invasion of U2OS cells by $51 \%$ (Fig. 3A) and MG63 cells by 58\% (Fig. 3B). The above data indicated that miR-448 can restrain osteosarcoma cell invasion.

AEG-1 is a direct target gene of miR-448. In order to decipher the molecular mechanism of miR-448 in osteosarcoma, bioinformatics analysis was performed to predict the functional targets of miR-448 using publicly available databases (TargetScan and miRanda). Notably, AEG-1 which is a well-known oncogene associated with osteosarcoma (23-25), was predicted to be a target gene of miR-448. The predicted binding sites of miR-448 within the wild-type (WT) 3'-UTR of AEG-1 are described in Fig. 4A. These sequences were mutated to generate the mutant (Mut) 3'-UTR of AEG-1, which does not bind miR-448 (Fig. 4A). To validate whether AEG-1 is the direct target gene of miR-448, dual-luciferase assays were performed. The WT or Mut 3'-UTR of AEG-1 
A

$$
\begin{gathered}
\text { 3' -uacccuguaggaugUAUACGUu-5' } \\
|||||| \mid \\
\text { 5' -cuguagugcguagaAUAUGCAu-3' } \\
\text { 5' -cuguagugcguagaAAAAGGAu-3' }
\end{gathered}
$$

B

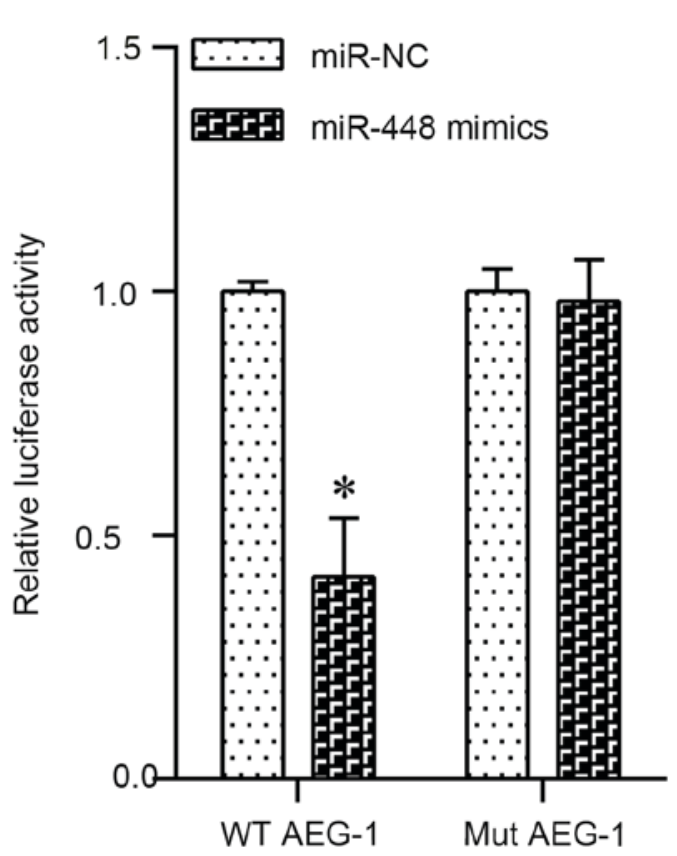

Hsa-miR-448

WT AEG-1 3'-UTR

Mut AEG-1 3'-UTR

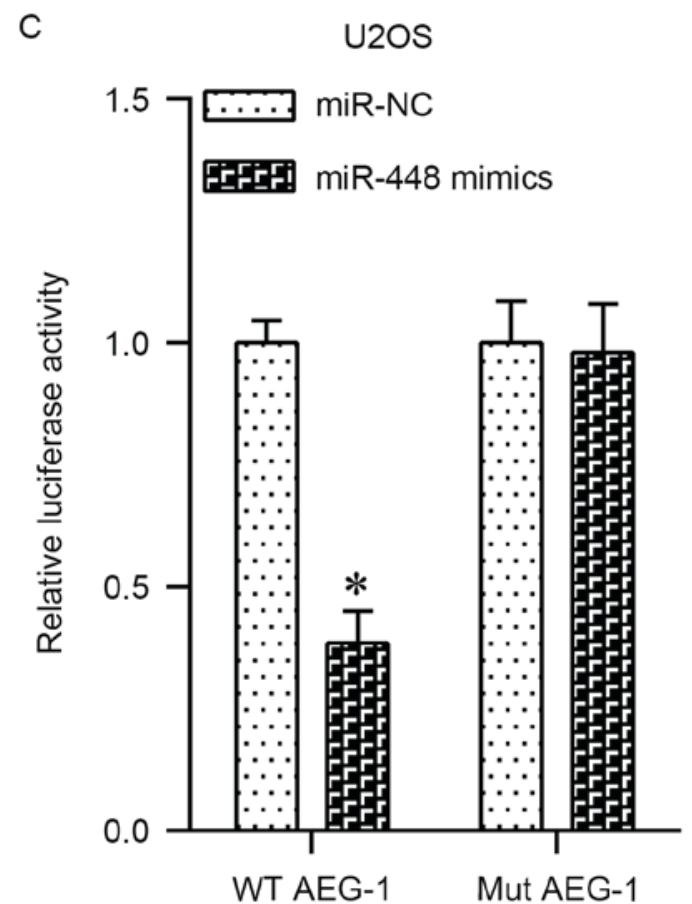

Figure 4. Effects of miR-448 on AEG-1. (A) Schematic diagram illustrating the miR-448 binding sites on the WT and mut form of 3'-UTR of AEG-1. The effects of WT or Mut 3'-UTR of AEG-1 on miR-448 or miR-NC, was demonstrated by dual-luciferase reporter assays in (B) MG63 and (C) U2OS cells. Data are expressed as the mean \pm standard deviation. ${ }^{*} \mathrm{P}<0.05$ vs. miR-NC. miR, microRNA; NC, negative control; WT, wild-type; Mut, mutated form; UTR, untranslated region; AEG-1, astrocyte elevated gene-1.

was cloned into the dual-luciferase reporter vector. MG63 and U2OS cells were transiently transfected with these constructs and miR-448 mimics or miR-NC. The luciferase activity generated by the reporter vector carrying the WT 3'-UTR of AEG-1 was markedly decreased by miR-448 overexpression, whereas the activity generated by the reporter vector with Mut 3'-UTR of AEG-1 was not affected by miR-448 overexpression (Fig. 4B and C). The effects of miR-448 overexpression on AEG-1 expression were also studied by RT-qPCR and western blot analysis. The results demonstrated that both mRNA and protein expression levels of AEG-1 were markedly decreased by miR-448 overexpression (Fig. 5A-D). Overall, these results indicated that AEG-1 is one of the functional target genes of miR-448.

Overexpression of $\mathrm{miR}-448$ inhibits Wnt and $N F-\kappa B$ signaling pathways. A previous study reported that AEG-1 regulates tumorigenesis through the Wnt and NF- $\mathrm{BB}$ signaling pathways (18). Considering the inhibitory effect of miR-448 on AEG-1, miR-448 was hypothesized to inhibit the Wnt and $\mathrm{NF}-\kappa \mathrm{B}$ signaling pathways. By performing luciferase reporter assays, both Wnt (Fig. 6A) and $\mathrm{NF}-\kappa \mathrm{B}$ (Fig. 6B) signaling pathways were markedly inhibited by miR-448 overexpression, indicating that miR-448 was a negative regulator of both Wnt and NF- $\mathrm{NB}$ signaling pathways.
AEG-1 is involved in miR-448-mediated antitumor effects. In order to investigate whether miR-448 exerts its antitumor effects through its target gene AEG-1, rescue experiments were performed. The results demonstrated that the decreased AEG-1 protein expression induced by miR-448 overexpression was significantly restored in cells co-transfected with pcDNA3.1/AEG-1 and miR-448 mimics (Fig. 7A and $\mathrm{B})$. Whether restoration of AEG-1 could reverse the miR-448-mediated inhibitory effects on osteosarcoma cell proliferation and invasion was also investigated. The results demonstrated that overexpression of AEG-1 markedly abrogated the miR-448-mediated inhibition on proliferation (Fig. 7C and D) and invasion (Fig. 7E and F) of osteosarcoma cells. Overexpression of AEG-1 also reversed the inhibitory effect of miR-448 overexpression on colony formation of osteosarcoma cells (data not shown). Furthermore, the miR-448-mediated inhibitory effect of AEG-1 overexpression on Wnt (Fig. 8A) and NF- $\mathrm{BB}$ (Fig. $8 \mathrm{~B}$ ) signaling pathways was also significantly reversed. Taken together, these results suggested that miR-448 exerts its antitumor role through AEG-1.

\section{Discussion}

Previous studies have revealed that miRNAs are critical regulators of osteosarcoma, making them potential therapeutic 
A

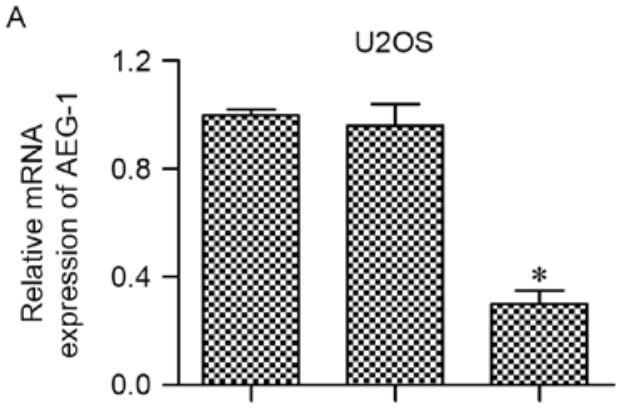

C

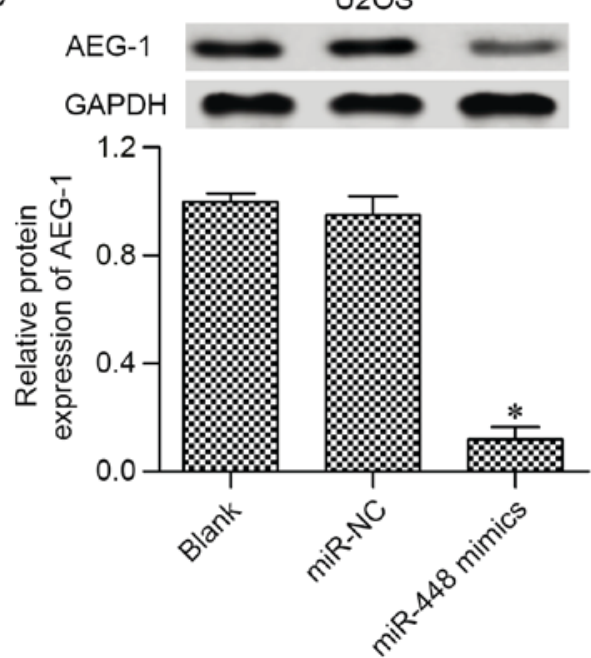

B

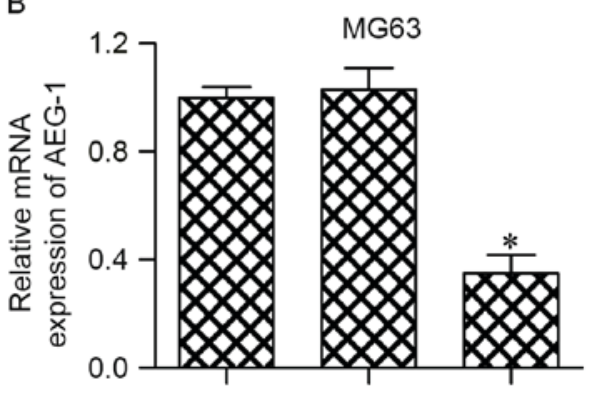

D
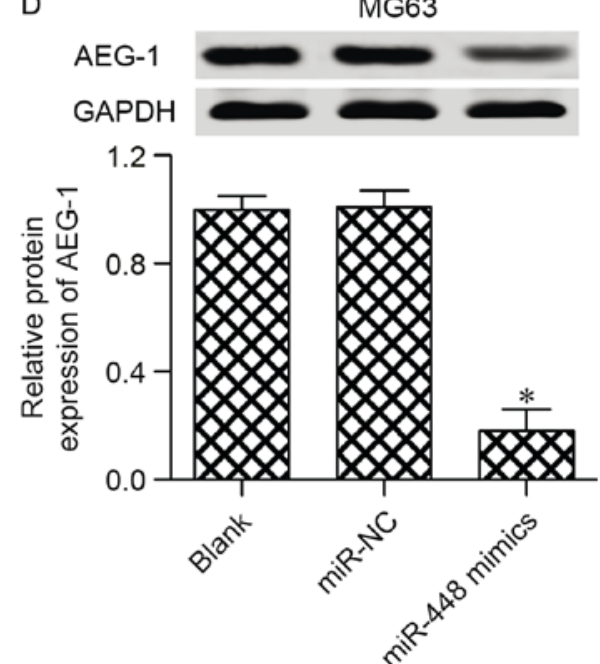

Figure 5. mRNA expression levels of AEG-1 in (A) U2OS and (B) MG63 cells as examined by reverse transcription-quantitative polymerase chain reaction analysis. The protein expression levels of AEG-1 in (C) U2OS and (D) MG63 cells were examined by western blot analysis. Data are expressed as the mean \pm standard deviation. ${ }^{*} \mathrm{P}<0.05$ vs. blank and miR-NC. miR, microRNA; NC, negative control; AEG-1, astrocyte elevated gene-1.

A

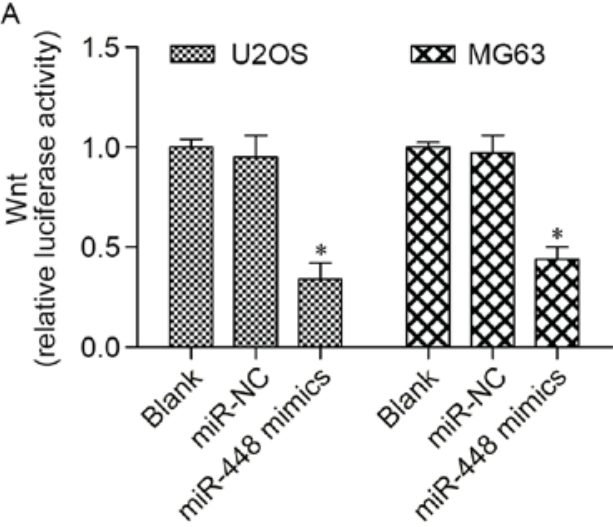

B

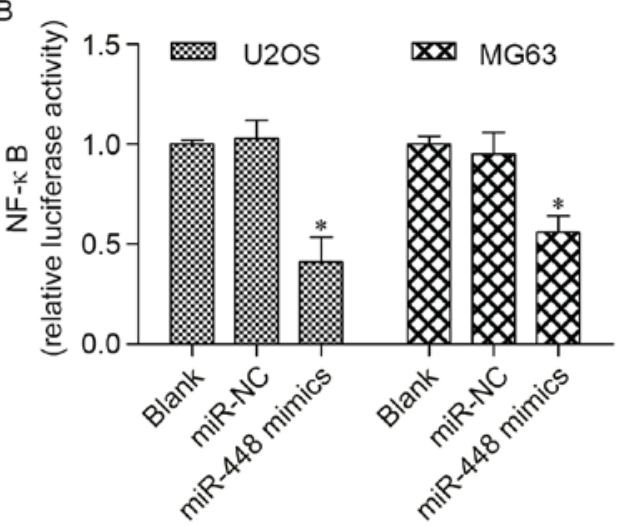

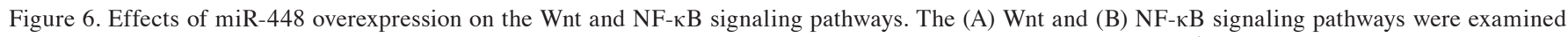
by luciferase reporter activity assays, in U2OS and MG63 cells. Data are expressed as the mean \pm standard deviation. ${ }^{*} \mathrm{P}<0.05 \mathrm{vs}$. blank and miR-NC. miR,

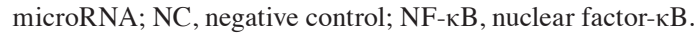

agents for its treatment (10). However, the exact role of miRNAs in osteosarcoma pathogenesis remains to be elucidated. In the present study, miR-448 was demonstrated as a novel miRNA involved in osteosarcoma development. miR-448 was downregulated in osteosarcoma, whereas the overexpression of miR-448 inhibited osteosarcoma cell proliferation and invasion. These data suggested that miR-448 might be associated with osteosarcoma development and progression and might be a promising diagnostic biomarker and a molecular target for osteosarcoma treatment.
Previous studies have reported an important role of miR-448 in regulating cancer development $(30,31)$. Low expression of miR-448 promotes the invasion of hepatocellular carcinoma cells by upregulating Rho-associated, coiled-coil-containing protein kinase-2 (32). miR-448 is downregulated in ovarian cancer, and overexpression of miR-448 inhibits cell growth and metastasis by targeting the chemokine C-X-C motif ligand-12 (26). In gastric cancer, miR-448 is downregulated and overexpression of miR-448 represses cell proliferation and invasion by regulating A disintegrin and metalloproteinase-10 (27). Li et al (33) reported 


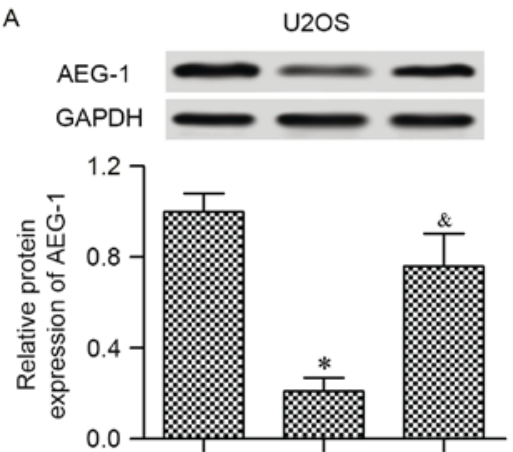

C
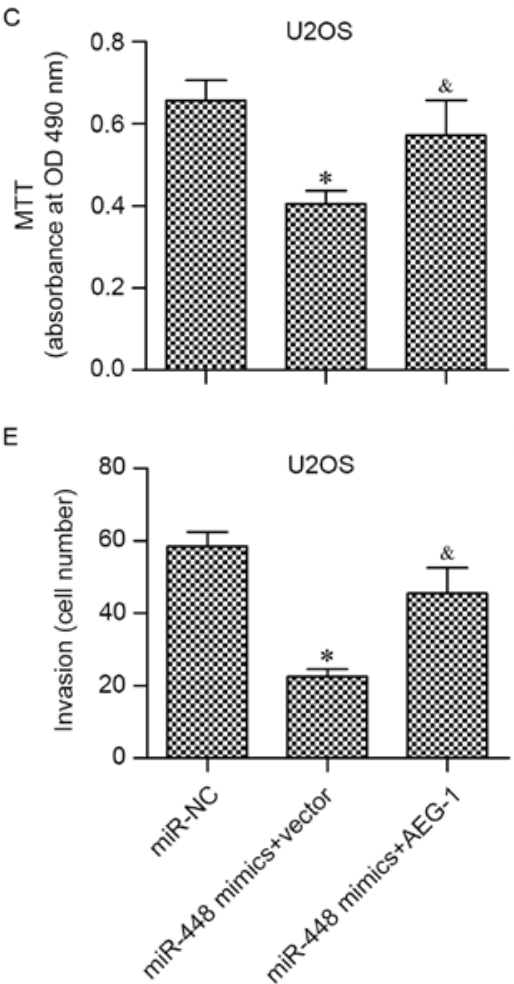

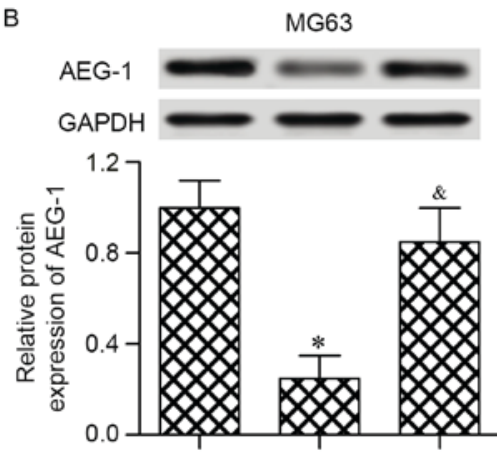

D

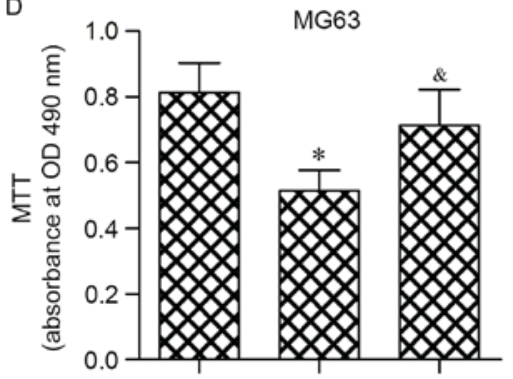

$\mathrm{F}$
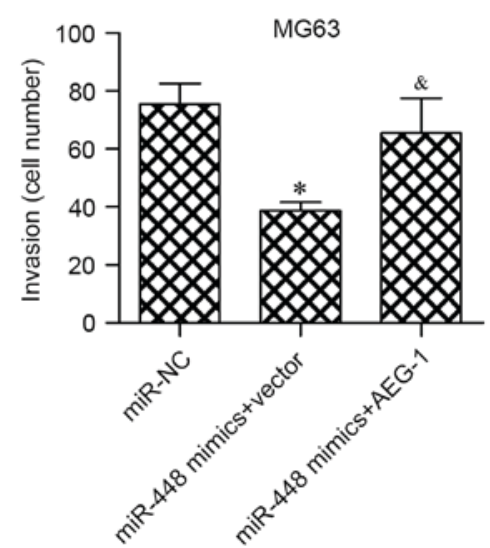

Figure 7. Protein expression levels of AEG-1 in (A) U2OS and (B) MG63 cells was detected by western blot analysis. Cell proliferation of (C) U2OS and (D) MG63 cells was determined by MTT assays. Cell invasion of U2OS (E) and MG63 (F) cells was examined by Transwell invasion assays. Data are expressed as the mean \pm standard deviation. ${ }^{\mathrm{P}} \mathrm{P}<0.05$ vs. miR-NC; ${ }^{\circledR} \mathrm{P}<0.05$ vs. miR-448 mimics and vector. miR, microRNA; NC, negative control; AEG-1, astrocyte elevated gene-1; OD, optical density.

A

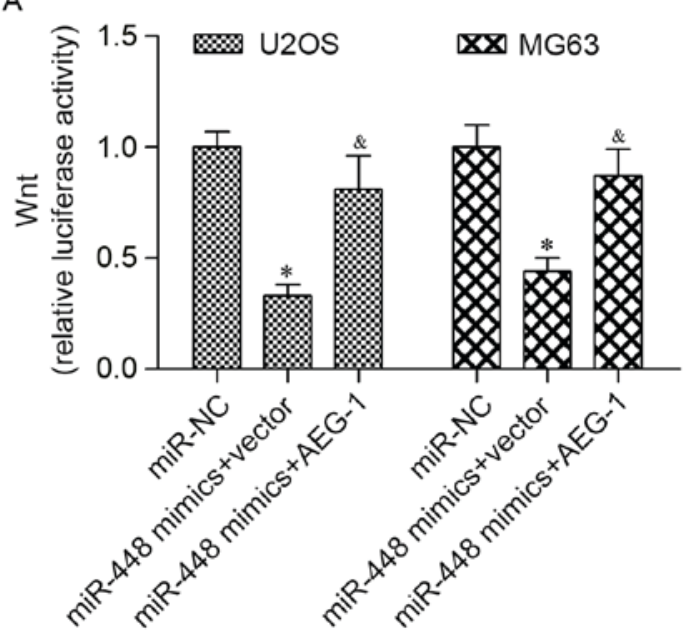

B

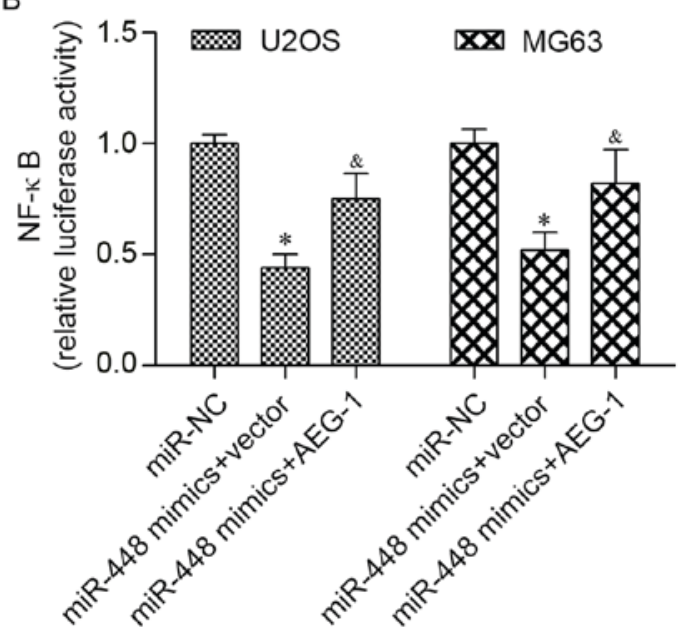

Figure 8. Effects of AEG-1 on the Wnt and NF- $\kappa$ B signaling pathways. miR-488-mediated inhibition of the (A) Wnt and (B) NF- $\kappa \mathrm{B}$ signaling pathways was detected by Tcf-dependent TOPFlash reporter activity assays, in U2OS and MG63 cells. Data are expressed as the mean \pm standard deviation. ${ }^{*} \mathrm{P}<0.05$

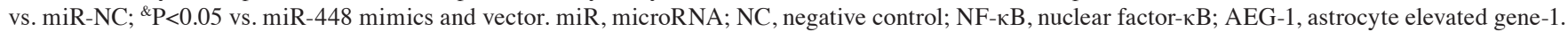


that miR-448 inhibits colorectal cancer cell proliferation and invasion by regulating insulin-like growth factor-1 receptor. In line with these findings, the present results indicated a putative tumor suppressor role of miR-448. miR-448 was decreased in osteosarcoma cell lines and inhibited cell proliferation and invasion. However, an oncogenic role of miR-448 has been reported in gastric cancer (28); miR-448 promoted glycolytic metabolism of gastric cancer by regulating lysine demethylase $2 \mathrm{~B}$, and high expression of miR-448 was associated with poor clinical outcomes (28). These studies suggested that the precise role of miR-448 in cancer development requires further investigation.

To investigate the underlying mechanism responsible for miR-448-mediated antitumor effects, the functional target gene of miR-448 in osteosarcoma cells was studied. Notably, AEG-1, a well-recognized oncogene (17), was identified as the target gene of miR-448. AEG-1 is overexpressed in various cancers and is associated with the activation of various oncogenic signaling pathways, including those of Akt, Wnt and NF- $\mathrm{NB}$, contributing to cancer cell proliferation and metastasis $(12,17)$. Overexpression of AEG-1 in osteosarcoma is associated with clinical grade, metastasis and poor survival (23). AEG-1 promotes osteosarcoma cell proliferation and invasion associated with upregulating the c-Jun N-terminal kinase/c-Jun/metalloproteinase-2 signaling pathway $(23,25,34)$. Furthermore, Liu et al (24) reported that AEG-1 promotes osteosarcoma cell invasion and chemoresistance by activating the endothelin-1/endothelin A receptor signaling pathway. In the present study, AEG-1 was involved in the miR-448-mediated cell proliferation and invasion. Overexpression of miR-448 inhibited AEG-1 and AEG-1-mediated Wnt and $\mathrm{NF}-\kappa \mathrm{B}$ signaling. The Wnt and $\mathrm{NF}-\kappa \mathrm{B}$ signaling pathways have been suggested as potential targets for preventing osteosarcoma $(35,36)$. Therefore, targeting AEG-1 by inhibiting Wnt and NF- $\mathrm{NB}$ signaling pathways via miR-448 may represent a novel therapeutic strategy for osteosarcoma.

A growing number of studies have reported that AEG-1 is regulated by numerous miRNAs in various cancers $(37,38)$. miR-542-3p, miR-217 and miR-497 have been reported to target AEG-1 by inhibiting cancer cell proliferation and invasion (39-41). Notably, a previous study reported that miR-506 inhibits osteosarcoma cell proliferation by targeting AEG-1 (42). In the present study, AEG-1 could be targeted by miR-448, suggesting a novel miRNA inhibitor of AEG-1. These studies indicated that AEG-1 is regulated by various miRNAs. The present study suggested that miR-448 may serve as a potential target for the treatment of AEG-1-associated cancers, at least in osteosarcoma.

In conclusion, the present study demonstrated an important role for miR-448 in osteosarcoma. miR-448 was downregulated in osteosarcoma and overexpression of miR-448 inhibited cell proliferation and invasion by targeting AEG-1, providing novel insights into the understanding of osteosarcoma pathogenesis. The present study suggested that miR-448 may represent a potential and promising miRNA for the development of miRNA-based therapy for osteosarcoma.

\section{References}

1. Botter SM, Neri D and Fuchs B: Recent advances in osteosarcoma. Curr Opin Pharmacol 16: 15-23, 2014.
2. Hughes DP: Strategies for the targeted delivery of therapeutics for osteosarcoma. Expert Opin Drug Deliv 6: 1311-1321, 2009.

3. Bartel DP: MicroRNAs: Genomics, biogenesis, mechanism, and function. Cell 116: 281-297, 2004.

4. Winter J, Jung S, Keller S, Gregory RI and Diederichs S: Many roads to maturity: MicroRNA biogenesis pathways and their regulation. Nat Cell Biol 11: 228-234, 2009.

5. Thomson DW, Bracken CP and Goodall GJ: Experimental strategies for microRNA target identification. Nucleic Acids Res 39: 6845-6853, 2011.

6. Manikandan J, Aarthi JJ, Kumar SD and Pushparaj PN: Oncomirs: The potential role of non-coding microRNAs in understanding cancer. Bioinformation 2: 330-334, 2008.

7. Pang JC, Kwok WK, Chen Z and Ng HK: Oncogenic role of microRNAs in brain tumors. Acta Neuropathol 117: 599-611, 2009.

8. Silber J, James CD and Hodgson JG: MicroRNAs in gliomas: Small regulators of a big problem. Neuromolecular Med 11: 208-222, 2009.

9. Kushlinskii NE, Fridman MV and Braga EA: Molecular mechanisms and microRNAs in osteosarcoma pathogenesis. Biochemistry (Mosc) 81: 315-328, 2016.

10. Sampson VB, Yoo S, Kumar A, Vetter NS and Kolb EA: MicroRNAs and potential targets in osteosarcoma: Review. Front Pediatr 3: 69, 2015.

11. Zhang J, Yan YG, Wang C, Zhang SJ, Yu XH and Wang WJ: MicroRNAs in osteosarcoma. Clin Chim Acta 444: 9-17, 2015.

12. Shi $X$ and Wang X: The role of MTDH/AEG-1 in the progression of cancer. Int J Clin Exp Med 8: 4795-4807, 2015.

13. Lee SG, Kang DC, DeSalle R, Sarkar D and Fisher PB: AEG-1/MTDH/LYRIC, the beginning: Initial cloning, structure, expression profile, and regulation of expression. Adv Cancer Res 120: 1-38, 2013.

14. Emdad L, Das SK, Dasgupta S, Hu B, Sarkar D and Fisher PB: AEG-1/MTDH/LYRIC: Signaling pathways, downstream genes, interacting proteins, and regulation of tumor angiogenesis. Adv Cancer Res 120: 75-111, 2013.

15. Emdad L, Das SK, Hu B, Kegelman T, Kang DC, Lee SG, Sarkar D and Fisher PB: AEG-1/MTDH/LYRIC: A promiscuous protein partner critical in cancer, obesity, and CNS diseases. Adv Cancer Res 131: 97-132, 2016.

16. Su ZZ, Kang DC, Chen Y, Pekarskaya O, Chao W, Volsky DJ and Fisher PB: Identification and cloning of human astrocyte genes displaying elevated expression after infection with HIV-1 or exposure to HIV-1 envelope glycoprotein by rapid subtraction hybridization, RaSH. Oncogene 21: 3592-3602, 2002.

17. Hu G, Wei Y and Kang Y: The multifaceted role of MTDH/AEG-1 in cancer progression. Clin Cancer Res 15: 5615-5620, 2009.

18. Huang Y and Li LP: Progress of cancer research on astrocyte elevated gene-1/Metadherin (Review). Oncol Lett 8: 493-501, 2014.

19. Lee SG, Su ZZ, Emdad L, Sarkar D and Fisher PB: Astrocyte elevated gene-1 (AEG-1) is a target gene of oncogenic Ha-ras requiring phosphatidylinositol 3-kinase and c-Myc. Proc Natl Acad Sci USA 103: 17390-17395, 2006.

20. Lee SG, Su ZZ, Emdad L, Sarkar D, Franke TF and Fisher PB: Astrocyte elevated gene-1 activates cell survival pathways through PI3K-Akt signaling. Oncogene 27: 1114-1121, 2008.

21. Emdad L, Sarkar D, Su ZZ, Randolph A, Boukerche H, Valerie K and Fisher PB: Activation of the nuclear factor kappaB pathway by astrocyte elevated gene-1: Implications for tumor progression and metastasis. Cancer Res 66: 1509-1516, 2006.

22. He W, He S, Wang Z, Shen H, Fang W, Zhang Y, Qian W, Lin M, Yuan J, Wang J, et al: Astrocyte elevated gene-1(AEG-1) induces epithelial-mesenchymal transition in lung cancer through activating Wnt/ $\beta$-catenin signaling. BMC Cancer 15: 107, 2015.

23. Wang F, Ke ZF, Sun SJ, Chen WF, Yang SC, Li SH, Mao XP and Wang LT: Oncogenic roles of astrocyte elevated gene-1 (AEG-1) in osteosarcoma progression and prognosis. Cancer Biol Ther 12: 539-548, 2011.

24. Liu B, Wu Y and Peng D: Astrocyte elevated gene-1 regulates osteosarcoma cell invasion and chemoresistance via endothelin-1/endothelin A receptor signaling. Oncol Lett 5: 505-510, 2013.

25. Wang F, Ke ZF, Wang R, Wang YF, Huang LL and Wang LT: Astrocyte elevated gene-1 (AEG-1) promotes osteosarcoma cell invasion through the JNK/c-Jun/MMP-2 pathway. Biochem Biophys Res Commun 452: 933-939, 2014.

26. Lv Y, Lei Y, Hu Y, Ding W, Zhang C and Fang C: MiR-448 negatively regulates ovarian cancer cell growth and metastasis by targeting CXCL12. Clin Transl Oncol 17: 903-909, 2015. 
27. Wu X, Tang H, Liu G, Wang H, Shu J and Sun F: MiR-448 suppressed gastric cancer proliferation and invasion by regulating ADAM10. Tumour Biol 37: 10545-10551, 2016.

28. Hong X, Xu Y, Qiu X, Zhu Y, Feng X, Ding Z, Zhang S, Zhong L, Zhuang Y, Su C, et al: MiR-448 promotes glycolytic metabolism of gastric cancer by downregulating KDM2B. Oncotarget 7: 22092-22102, 2016.

29. Livak KJ and Schmittgen TD: Analysis of relative gene expression data using real-time quantitative PCR and the 2(-Delta Delta C(T)) method. Methods 25: 402-408, 2001.

30. Li QQ, Chen ZQ, Cao XX, Xu JD, Xu JW, Chen YY, Wang WJ, Chen Q, Tang F, Liu XP and Xu ZD: Involvement of $\mathrm{NF}-\kappa \mathrm{B} / \mathrm{miR}-448$ regulatory feedback loop in chemotherapy-induced epithelial-mesenchymal transition of breast cancer cells. Cell Death Differ 18: 16-25, 2011

31. Bamodu OA, Huang WC, Lee WH, Wu A, Wang LS, Hsiao M, Yeh CT and Chao TY: Aberrant KDM5B expression promotes aggressive breast cancer through MALAT1 overexpression and downregulation of hsa-miR-448. BMC Cancer 16: 160, 2016

32. Zhu H, Zhou X, Ma C, Chang H, Li H, Liu F and Lu J: Low expression of miR-448 induces EMT and promotes invasion by regulating ROCK2 in hepatocellular carcinoma. Cell Physio Biochem 36: 487-498, 2015.

33. Li B, Ge L, Li M, Wang L and Li Z: MiR-448 suppresses proliferation and invasion by regulating IGF1R in colorectal cancer cells. Am J Transl Res 8: 3013-3022, 2016.

34. Wang Z, Cao CJ, Huang LL, Ke ZF, Luo CJ, Lin ZW, Wang F, Zhang YQ and Wang LT: EFEMP1 promotes the migration and invasion of osteosarcoma via MMP-2 with induction by AEG-1 via NF-кB signaling pathway. Oncotarget 6: 14191-14208, 2015.

35. Lin CH, Ji T, Chen CF and Hoang BH: Wnt signaling in osteosarcoma. Adv Exp Med Biol 804: 33-45, 2014.
36. Zhang CL, Wang C, Yan WJ, Gao R, Li YH and Zhou XH: Knockdown of TNFAIP1 inhibits growth and induces apoptosis in osteosarcoma cells through inhibition of the nuclear factor- $\kappa \mathrm{B}$ pathway. Oncol Rep 32: 1149-1155, 2014.

37. He XX, Chang Y, Meng FY, Wang MY, Xie QH, Tang F, Li PY, Song YH and Lin JS: MicroRNA-375 targets AEG-1 in hepatocellular carcinoma and suppresses liver cancer cell growth in vitro and in vivo. Oncogene 31: 3357-3369, 2012.

38. Nohata N, Hanazawa T, Kikkawa N, Mutallip M, Sakurai D, Fujimura L, Kawakami K, Chiyomaru T, Yoshino H, Enokida H, et al: Tumor suppressive microRNA-375 regulates oncogene AEG-1/MTDH in head and neck squamous cell carcinoma (HNSCC). J Hum Genet 56: 595-601, 2011.

39. Shen X, Si Y, Yang Z, Wang Q, Yuan J and Zhang X: MicroRNA-542-3p suppresses cell growth of gastric cancer cells via targeting oncogene astrocyte-elevated gene-1. Med Oncol 32: 361, 2015.

40. Wang B, Shen ZL, Jiang KW, Zhao G, Wang CY, Yan YC, Yang Y, Zhang JZ, Shen C, Gao ZD, et al: MicroRNA-217 functions as a prognosis predictor and inhibits colorectal cancer cell proliferation and invasion via an AEG-1 dependent mechanism. BMC Cancer 15: 437, 2015.

41. Yan JJ, Zhang YN, Liao JZ, Ke KP, Chang Y, Li PY, Wang M, Lin JS and He XX: MiR-497 suppresses angiogenesis and metastasis of hepatocellular carcinoma by inhibiting VEGFA and AEG-1. Oncotarget 6: 29527-29542, 2015.

42. Yao J, Qin L, Miao S, Wang X and Wu X: Overexpression of miR-506 suppresses proliferation and promotes apoptosis of osteosarcoma cells by targeting astrocyte elevated gene-1. Oncol Lett 12: 1840-1848, 2016 